\title{
A COBRANÇA PELO USO DOS RECURSOS HÍDRICOS COMO ESTRATÉGIA PARA SEU USO SUSTENTÁVEL NO BRASIL
}

\author{
Fábio Augusto Alho da Costa*
}

Resumo: A Política Nacional dos Recursos Hídricos integrou a gestão de recursos hídricos, seu foco é reduzir os conflitos de uso e garantir a qualidade e quantidade da água. Dentre seus instrumentos, a cobrança visa promover o uso racional da água. Este trabalho objetivou identificar o estágio de implementação deste instrumento, bem como seus desafios e perspectivas, visando trazer a sua importância para a democratização do acesso à água. Tratase de uma pesquisa qualitativa descritiva. Observou-se que que há um desafio na efetiva cobrança bem com um incentivo ao consumo e exaustão do recurso.

Palavras-chaves: Sustentabilidade. Gestão de recursos hídricos. Cobrança pelo uso. Instrumentos de gestão de recursos hídricos. Conflitos pela Água

\section{CHARGING THE USE OF WATER RESOURCES AS A STRATEGY FOR ITS SUSTAINABLE USE IN BRAZIL}

\begin{abstract}
The National Water Resources Policy has integrated the management of water resources, its focus is to reduce conflicts of use and guarantee the quality and quantity of water. Among its instruments, the charge aims to promote the rational use of water. This work aimed to identify the stage of implementation of this instrument, as well as its challenges and perspectives, aiming to bring its importance to the democratization of access to water. It is a descriptive qualitative research. It was observed that there is a challenge in effective collection as well as an incentive to consumption and resource exhaustion.
\end{abstract}

Keywords: Sustainability. Water resource management. Charge for use. Water resources management instruments. Conflicts over water

\section{Introdução}

A discussão sobre o uso dos recursos hídricos e suas consequências para as próximas gerações ganhou espaço há muitas décadas no cenário mundial, ensejando em diferentes necessidades de tomadas de decisão por parte dos governantes. No Brasil, a gestão dos recursos hídricos passou por diferentes momentos, sendo um marco importante a instituição da Política Nacional de Recursos Hídricos - PNRH, através da Lei Federal nº. 9.433/1997. Tal norma buscou propor uma gestão integrada com foco em reduzir os conflitos de uso e garantir a qualidade e quantidade da água para suprir as demandas (atuais e futuras) por tal recurso.

\footnotetext{
* Mestrando em Ciência Jurídica - UNIVALI. Diretor-Presidente da Agência Reguladora dos Serviços Públicos Delegados do Município de Manaus - AGEMAN. E-mail: fabioalho@hotmail.com.
} 
Entre os instrumentos propostos pela PNRH, está a Cobrança pelo uso dos recursos hídricos, que parte da visão da água como um bem público cuja maneira de induzir ao melhor uso seria utilizando seu valor econômico enquanto insumo produtivo.

Apesar de seu interesse, é de se entender que a aplicação efetiva da Cobrança no Brasil possa ocorrer de forma lenta, especialmente por que os grandes usuários do recurso aqueles que mais pagariam pelo mesmo, por dever - não possuem interesse nisso. Até o ano de 2015, por exemplo, apenas seis unidades federativas estavam aplicando a cobrança. Não apenas aplicar, mas também aplicar com regras que não permitam o mau uso do recurso é essencial para que tal instrumento tenha eficácia em seus objetivos.

Nesse sentido, o presente trabalho teve como objetivo descrever a eficácia do instrumento de Cobrança pelo uso dos recursos hídricos em promover uma atitude sustentável em relação a esses recursos no Brasil desde a implantação do marco regulatório. Alguns aspectos foram utilizados para isso: verificação da implementação da cobrança, arrecadação dos valores cobrados e regras para cobrança.

A pesquisa se caracteriza como qualitativa, utilizando o método indutivo ${ }^{1} \mathrm{e}$ empregando técnicas da Pesquisa Bibliográfica ${ }^{2}$, do Referente $^{3}$, da Categoria ${ }^{4}$ e do Conceito Operacional $^{5}$.método indutivo ${ }^{6}$ e empregou técnicas da Pesquisa Bibliográfica ${ }^{7}$, do Referente $^{8}$, da Categoria ${ }^{9}$ e do Conceito Operacional ${ }^{10}$.

\footnotetext{
1 “[...] pesquisar e/ou identificar as partes de um fenômeno e coleciona-las de modo a ter uma percepção ou conclusão geral [...]". PASOLD, César Luiz. Metodologia da Pesquisa Jurídica: teoria e prática. 14 ed. Florianópolis: EMais, 2018. p. 94.

2 "Técnica de investigação em livros, repertórios jurisprudenciais e coletâneas legais". PASOLD, César Luiz. Metodologia da Pesquisa Jurídica: teoria e prática. p. 217.

3 “[...] explicitação prévia do(s) motivo(s), do(s) objetivo(s) e do produto desejado, delimitando o alcance temático e de abordagem para a atividade intelectual, especialmente para uma pesquisa." PASOLD, César Luiz. Metodologia da Pesquisa Jurídica: teoria e prática. p. 61.

4 “[...] palavra ou expressão estratégica à elaboração e/ou à expressão de uma ideia." PASOLD, César Luiz. Metodologia da Pesquisa Jurídica: teoria e prática. p.31.

5 “[...] uma definição para uma palavra ou expressão, com o desejo de que tal definição seja aceita para os efeitos das ideias que expomos [...]". PASOLD, César Luiz. Metodologia da Pesquisa Jurídica: teoria e prática. p. 43.

6 " "...] pesquisar e/ou identificar as partes de um fenômeno e coleciona-las de modo a ter uma percepção ou conclusão geral [...]". PASOLD, César Luiz. Metodologia da Pesquisa Jurídica: teoria e prática. 14 ed. Florianópolis: EMais, 2018. p. 94.

7 "Técnica de investigação em livros, repertórios jurisprudenciais e coletâneas legais". PASOLD, César Luiz. Metodologia da Pesquisa Jurídica: teoria e prática. p. 217.

8 “"...] explicitação prévia do(s) motivo(s), do(s) objetivo(s) e do produto desejado, delimitando o alcance temático e de abordagem para a atividade intelectual, especialmente para uma pesquisa." PASOLD, César Luiz. Metodologia da Pesquisa Jurídica: teoria e prática. p. 61.

9 “[...] palavra ou expressão estratégica à elaboração e/ou à expressão de uma ideia." PASOLD, César Luiz. Metodologia da Pesquisa Jurídica: teoria e prática. p.31.
} 
O texto segue uma ordem lógica, que inicia abordando a gestão dos recursos hídricos no Brasil, bem como os instrumentos propostos pela PNRH. Após, traz-se aspectos conceituais da Cobrança pelo uso dos recursos hídricos, bem como a evolução das experiências brasileiras. Por fim, trata da relação entre a Cobrança e a sustentabilidade, seguida das considerações que puderam ser obtidas no decorrer do trabalho.

\section{Gestão dos recursos hídricos no Brasil}

As tendências mundiais e nacionais em relação ao gerenciamento dos recursos hídricos auxiliam no entendimento de seu significado para a sociedade em diferentes épocas. Rosa \& Guarda (2019, p. 199) apresentam uma perspectiva histórica da gestão das águas no Brasil, salientando que tal fenômeno não é recente no país e que o entendimento dos usos da água no passado possibilita um planejamento melhor do futuro e um uso mais sustentável da água.

Os autores ainda apontam que no Brasil pré-colonial, por exemplo, a água não sofria com grandes usos por parte dos indígenas aqui residentes - em alguns casos, inclusive, era tratada como especial e sagrada - e isso permitiu sua conservação durante tal período. Durante o período colonial, no entanto, houve uma maior necessidade de utilização de tais recursos. Nessa época, a economia estava ligada à exploração intensiva de recursos naturais, e sua disponibilidade foi de grande importância para tal exploração ${ }^{11}$.

Após isso, iniciou-se um processo de legislação que visava o controle das atividades exploratórias, ainda sem o intuito preservacionista, porém já apresentava critérios de utilização dos recursos hídricos. Na próxima fase, chamada pelas autoras de holística, iniciouse a preocupação com o uso sustentável da água, trazendo a Lei da Política Nacional de Recursos Hídricos e uma proposta de gestão integrada com foco em reduzir os conflitos de uso e garantir a qualidade e quantidade da água para suprir as demandas (atuais e futuras).

\footnotetext{
10 “[...] uma definição para uma palavra ou expressão, com o desejo de que tal definição seja aceita para os efeitos das ideias que expomos [...]”. PASOLD, César Luiz. Metodologia da Pesquisa Jurídica: teoria e prática. p. 43.

11 " $\mathrm{Na}$ primeira fase que vai do descobrimento até 1930, nas regulamentações ambientais, não é observada preocupação com o meio ambiente, exceto pela proteção de recursos naturais que tinham valor econômico para a metrópole, não se incluindo a água. Nesse período, a grande quantidade de água existente influenciou na colonização do território, na cultura e na relação da sociedade com a natureza. Nessa época, parte da população sofria com a falta de abastecimento, principalmente a com menos recursos financeiros." ROSA, A. M. R.; GUARDA, V. L. M. Gestão de recursos hídricos no Brasil: um histórico. p. 215.
} 
A Política Nacional de Recursos Hídricos - PNRH, instituída através da Lei Federal n. 9.433/1997, propôs cinco instrumentos para a gestão: i) o Plano de recursos hídricos; ii) o enquadramento dos corpos d'água em classes; iii) a outorga dos direitos de uso de recursos hídricos; iv) o Sistema Nacional de Informações sobre Recursos Hídricos (SNIRH); e v) a outorga de direitos de uso de tais recursos e a cobrança por tal uso.

Dentro do PNRH, a adoção das Bacias Hidrográficas, teve como resultado a integração entre o gerenciamento destes recursos hídricos e a gestão ambiental, possibilitando a mobilização dos agentes (população, usuários diretos, setor público) que se beneficiam destes corpos de água no sentido de sua preservação, entretanto, apesar dos avanços possibilitados o sistema ainda possui traços de injustiças ambientais dada a assimetria dentre os poderes que constam no sistema.

Os Planos de Recursos Hídricos são planos diretores que visam a fundamentar e orientar a implementação da PNRH e o gerenciamento desses recursos. São de longo prazo e devem possuir um conteúdo mínimo, que inclui, entre outros itens, o diagnóstico da situação atual desses recursos, análise sobre alterações em aspectos demográficos e econômicos e de ocupação do solo e o balanço entre a disponibilidade e as demandas futuras desses recursos.

O enquadramento dos corpos d'água em classes ocorre de acordo com o uso preponderante do recurso e visa assegurar sua qualidade de forma compatível aos usos mais exigentes aos quais será destinada, bem como reduzir os custos com combate à poluição.

A outorga de direitos de uso tem como objetivo assegurar o controle qualitativo e quantitativo dos usos da água e o efetivo exercício dos direitos de acesso à mesma e se dará por ato da autoridade competente do Poder Executivo Federal, dos Estados ou do Distrito Federal, de acordo com o corpo hídrico ao qual faz referência.

Logo, observa-se que a instituição da PNRH se constituiu como não apenas necessária para os instrumentos de gestão como um movimento natural desta regulamentação, que, ao instituir os instrumentos de gestão possibilita a manutenção deste recurso de extremo valor para a manutenção do todo o contexto social e econômico que tangencia as relações do Brasil.

A estrutura organizacional se encontra delimitada pelo Sistema Nacional de Gerenciamento de Recursos Hídricos, que é composto, segundo a ANA (2021) pela Secretaria de Recursos Hídricos e Qualidade Ambiental (CERH), pelo Conselho Nacional de Recursos Hídricos (CNRH), pela Agência Nacional de Águas, pelos conselhos estaduais de Recursos 
Hídricos (CERH), pelas entidades estaduais, pelos comitês de bacia hidrográficas e pelas Agências de Água e pela Secretaria.

\section{Marcos Teóricos da Cobrança pelo uso dos Recursos Hídricos}

Quando se considera a interferência humana no contexto das políticas públicas, é imprescindível a análise dos mecanismos de incentivos para que tal comportamento seja desenvolvido. Para Foucault (1975) se faz necessário, para que a vigilância hierárquica surta efeitos que esteja acompanhada da sanção normalizadora. Estas sanções objetivam ir além de uma punição propriamente dita, mas correspondem a mecanismos de desestímulo econômico, visto que, sem sua aplicação e, dado o caráter de retorno econômico do uso indiscriminado do recurso, ocorreria, em momento ulterior, o esgotamento deste recurso.

É visando então esta manutenção do recurso, bem como a garantia de sua qualidade que instrumentos de cobrança são empregados. Em um contexto econômico, essa cobrança tem duas finalidades que dão características fundamentais, sendo elas: i) A possibilidade de arrecadar montantes para desenvolvimento de novas políticas de gestão e implementar novos mecanismo para a manutenção dos níveis ótimos destes recursos; ii) $\mathrm{O}$ desincentivo econômico para o uso indiscriminado do recurso. Ambos os pontos resguardam resultados dentro do campo da ação dos agentes consumidores destes recursos, entretanto, o segundo funciona de uma forma Mengeriana Ao defrontar o valor de uso do recurso hídrico com o valor de uso da unidade monetária, faz-se necessário a análise individual do agente da real necessidade do consumo deste recurso face a possibilidade de consumo, em outros gêneros de bens, utilizando estes valores monetários. Isto é, ao definir valor para uso, se objetiva o critério da racionalidade do consumo, reduzindo-o por consequência.

Ainda nesta análise, faz sentido ante o exposto que os valores cobrados, assim como a lógica da progressividade tributária, sejam mais incisivos frente aos agentes que consomem mais do recurso, isto é, não faz sentido onerar um agente familiar, que tem seu consumo virtualmente voltado para atividades de manutenção de sua existência da mesma forma que se onera um agente econômico industrial, e.g., um grande produtor de bebidas, que além de ter o consumo maior que o do agente familiar, tem resultados econômicos ante a exploração deste recurso 
Ainda na análise do marco legal para a cobrança, ainda na lei 9.433/97, no Art. 19 todos os tópicos suscitados anteriormente são ratificados, conforme a seguir:

Art. 19. A cobrança pelo uso de recursos hídricos objetiva:

I - reconhecer a água como bem econômico e dar ao usuário uma indicação de seu real valor;

II - incentivar a racionalização do uso da água;

III - obter recursos financeiros para o financiamento dos programas e intervenções contemplados nos planos de recursos hídricos.

Logo, evidencia-se que a cobrança deve ser realizada dentro do contexto de uso e exploração de qualquer recurso como mecanismo para assegurar sua manutenção e preservação, ficando à cargo, no caso presente, do poder público a realização destas cobranças, a serem discutidas no subtópico posterior.

\section{Mecanismos de Implementação e de Cobrança}

Evidenciada a necessidade de cobrança pelo recurso, se faz necessário a discussão de como estes valores serão arrecadados é necessário a observação das particularidades presentes nestas Bacias, bem como os estágios da gestão regulatória, definidos pelos Comitês e Conselhos de Recursos Hídricos.

Para que seja implementada a cobrança, é necessário a identificação prévia dos usos aos quais os corpos d'água serão sujeitos, usos estes vinculados a outorga destes recursos que, apesar de não ser fixado por estes comitês, eles são responsáveis pela definição dos limites para dispensa de exigibilidade, conforme art. 37 da lei $n^{\circ}$ 9.433/97.

A aplicabilidade de cobrança pelo uso e outorga desses recursos encontra-se no Art. 12 a Lei 9.344/97 (DA POLÍTICA NACIONAL DE RECURSOS HÍDRICOS), com a seguinte redação:

Art. 12. Estão sujeitos a outorga pelo Poder Público os direitos dos seguintes usos de recursos hídricos:

I - Derivação ou captação de parcela da água existente em um corpo de água para consumo final, inclusive abastecimento público, ou insumo de processo produtivo;

II - Extração de água de aquífero subterrâneo para consumo final ou insumo de processo produtivo;

III - Lançamento em corpo de água de esgotos e demais resíduos líquidos ou gasosos, tratados ou não, com o fim de sua diluição, transporte ou disposição final; IV - Aproveitamento dos potenciais hidrelétricos;

$\mathrm{V}$ - Outros usos que alterem o regime, a quantidade ou a qualidade da água existente em um corpo de água. 
Superada a definição de necessidades de outorga, faz-se necessário a definição das etapas para que se efetive a cobrança. Entretanto, prévio a este procedimento, faz-se necessária a discussão do comitê, uma vez que é composto de diversos segmentos que agenciam interesses distintos, fazendo-se necessário a conciliação desses interesses, ou, no mínimo, a convergência em sentido mais aproximado e que possam optar por posicionamentos que são favoráveis as cobranças a serem implementadas.

Com essa conciliação, segue-se para a efetiva implementação de um plano de cobrança, que ocorre dentro da seguinte estrutura de etapas orientadas pelo volume 7 do caderno de capacitação da $\operatorname{ANA}(2014)$ : i) Construção da Proposta de mecanismos de cobrança: Se constitui na formação de um grupo técnico (com representação dos segmentos do comitê) que aprofundará o debate dos mecanismos frente a realidade da cobrança; ii) Construção das Propostas de Valores de Cobrança: Vinculando aos mecanismos previamente definidos valores para sua efetivação (considerando o incentivo econômico da cobrança), deve ser considerado o potencial de efetivo de arrecadação dos componentes de uso dos Recuros; e iii) Aprovação pelo Conselho de Recursos Hídricos: Ocorrendo da base da operação até a sua efetiva aprovação pelo Conselho de Recursos Hídricos.

O Art 21. da lei 9.433/97 define os critérios para observação quanto aos valores a serem cobrados pelo uso dos recursos hídricos, com a seguinte redação:

\footnotetext{
Art. 21. Na fixação dos valores a serem cobrados pelo uso dos recursos hídricos devem ser observados, dentre outros:

I - nas derivações, captações e extrações de água, o volume retirado e seu regime de variação;

II - nos lançamentos de esgotos e demais resíduos líquidos ou gasosos, o volume lançado e seu regime de variação e as características físico-químicas, biológicas e de toxidade do afluente
}

Isto é, pode-se entender que existem duas fases para a cobrança, a primeira trata do uso do recurso quando ainda na natureza, isto é, o consumo e esgotamento do recurso, o segundo ponto abordado trata do descarte nestes corpos d'água dos resíduos gerados por seu uso e consumo, definindo critérios que, ao passo que cobram pela redução do recurso disponível cobram também por toda e qualquer redução da qualidade dos valores residuais da disponibilidade, possibilitando então garantir níveis mínimos de qualidade e quantidade aceitáveis para conciliar a atividade econômica e uso social com a perpetuação do recurso para futuras gerações. 
Para a definição destes valores a serem cobrados, se fazem necessárias a análise de 3 componentes, sendo estes: i) Base de Cálculo; ii) Preço Unitário; e iii) Coeficientes Multiplicadores.

O primeiro item visa a quantificação (em termos de volume) dos valores utilizados do recurso para captação, lançamento, transposição e consumo. Corresponde então, de fato a base de consumo para definição dos cálculos de custo e de valores a serem recolhidos face ao consumo realizado, se difere de corpo d'água para corpo d'água, visto que as atividades nele desempenhadas variam tanto pelas capacidades de fornecimento próprias da bacia quanto pelas características socioeconômicas da região residente em seus entornos.

O item ii corresponde aos valores cobrados por tipo de utilização (sempre com base o item anterior). Estes valores são definidos em discussão de comitê através dos estudos previamente realizados e explicados em tópico anterior, considerando o potencial de arrecadação quando defrontado a sua capacidade de efetivação, isto é, o potencial econômico do recurso quando defrontado com a efetiva atividade da região do qual ele faz parte.

A definição deste preço, segundo a ANA (2014) se desenvolve através de simulações de potencial de arrecadação com base em dados de cadastro dos usuários, considerando itens como sua demanda de uso e tipo de demanda, permitindo a formação de uma cesta de preços para estas diversas aplicabilidades.

O terceiro e final ponto corresponde aos multiplicadores que podem ser aplicados, justamente devido aos critérios de valor de uso quando defrontado as escalas da atividade econômica, nos grandes usuários, i.e, aqueles que, devido a seu uso elevado do recurso o limitam para futuros usuários, tanto em critérios quantitativos quanto qualitativos.

Outrossim, esses mecanismos visam ajustar a cobrança aos fatores característicos da bacia, e.g, ajustando aos períodos de estiagem destes corpos, ajustando a movimentação natural de sazonalidade de um bem, estes valores mais elevados funcionam, assim como a cobrança propriamente dita como incentivos bifásicos, isto é, estimulam o arrecadador a utilizá-los para reinvestir na manutenção do recurso, bem como estimula o agente (neste caso, o responsável pelo pagamento) a adotar novas tecnologias de consumo, como mecanismos de reaproveitamento. Esses multiplicadores são definidos com base em balanço hídrico, que mede os valores do recurso e sua sazonalidade.

\section{Evolução das experiências brasileiras}


Como exposto previamente, a implementação desse instrumento de cobrança e gestão apresenta diferenças: i) Entre estados; e ii) Entre Bacias localizadas no mesmo estado. Essas diferenças são resultado das peculiaridades de cada bacia e do contexto da região na qual está inserida.

Em relação ao âmbito estadual, de 1996 a 2015, 6 foram os estados que iniciaram a cobrança segundo a ANA (2019, p. 23): (Ceará-1996; Rio de Janeiro-2004; São Paulo-2007; Minas Gerais-2010, Paraná-2013 e Paraíba-2015), essa elevada defasagem temporal entre a legislação que regulamenta esses recursos e sua efetiva cobrança acabam por gerar efeitos adversos e externalidades que, dada sua continuidade por elevado período podem gerar, ainda, perpetuação de seus efeitos.

Para efeitos de comparação, segundo relatório de 2012 dos totais de valores arrecadados com essa cobrança dos recursos, $63 \%$ do montante foi arrecadado exclusivamente pelos estados do Rio de Janeiro, São Paulo e Minas Gerais, isto é, ao ser confrontado com a data de início de cobrança, 35\% destes valores tiveram sua cobrança iniciada em 2004, 40\% só começaram a ser cobrados 3 anos depois, em 2007 e, novamente após 3 anos, 26\% desse percentual teve sua cobrança iniciada, demonstrando a existência de grande defasagem temporal no início de recolhimento destas receitas e resultando em diminuição do potencial econômico dos estados aos quais essas bacias estão atreladas a realizarem investimentos e possibilitando um sucateamento dos mecanismos de cobrança e regulação, pois, se a política teve sua origem em 1997 e a primeira cobrança ocorreu apenas em 2004, a defasagem temporal acaba por: i) Atrasar a efetiva implementação de políticas para o gerenciamento e manutenção destes recursos; ii) Possibilitar o esgotamento e redução da qualidade destes recursos durante sua implementação; iii) Reduzir o valor econômico deste recurso, por esgotamento e diminuição da qualidade; iv) Incapacitar o estado de arrecadar valores suficientes para a manutenção destes mecanismo. Logo, esse atraso acaba por ter efeito multiplicador negativo nos mecanismos de cobrança e no recurso como bem econômico.

Em termos históricos, a arrecadação se distribui da seguinte forma: i) Ceará: $36 \%$ da arrecadação histórica; ii) Corpos Interestaduais: 22\% da arrecadação histórica; iii) São Paulo: $20 \%$ da arrecadação histórica; iv) Rio de Janeiro: 12\% da arrecadação histórica; v) Minas 
Gerais: 9\% da arrecadação histórica; O saldo residual divide-se nos estados do Paraná e da Paraíba.

No âmbito federal, a cobrança ainda vem sendo instituída, tendo como último marco o início da cobrança nas bacias do rio Paranaíba e do rio Verde Grande em 2017 (20 anos após o PNRH) e ocorre elevada flutuação entre os valores cobrados, alinhado aos conceitos de atividade econômica e uso anteriormente elencados. O quadro a seguir demonstra a variação entre os valores cobrados (de acordo com a aplicação do recurso) por m3 do consumo do recurso e, no caso do lançamento de efluentes, por quilograma lançado.

\begin{tabular}{|c|c|c|c|c|c|c|c|c|c|c|}
\hline \multirow[t]{2}{*}{ Legenda } & \multicolumn{2}{|c|}{$\begin{array}{l}\text { Bacia do Rio } \\
\text { Paraíba do Sul }\end{array}$} & \multicolumn{2}{|c|}{$\begin{array}{l}\text { Bacia do Rio São } \\
\text { Francisco }\end{array}$} & \multicolumn{2}{|c|}{$\begin{array}{l}\text { Bacia do Rio } \\
\text { Doce }\end{array}$} & \multicolumn{2}{|c|}{$\begin{array}{l}\text { Bacia do Rio } \\
\text { Paranaíba }\end{array}$} & \multicolumn{2}{|c|}{$\begin{array}{l}\text { Bacia do Rio } \\
\text { Verde Grande }\end{array}$} \\
\hline & 2003 & 2019 & 2010 & 2019 & 2011 & 2019 & 2017 & 2019 & 2010 & 2019 \\
\hline $\begin{array}{l}\text { Captação de Água Bruta } \\
(\mathrm{R} \$ / \mathrm{m} 3)\end{array}$ & $\begin{array}{l}\mathrm{R} \$ \\
0,0080\end{array}$ & $\begin{array}{l}\mathrm{R} \$ \\
0,0158\end{array}$ & $\begin{array}{l}\mathrm{R} \$ \\
0,0100\end{array}$ & $\begin{array}{l}\mathrm{R} \$ \\
0,0120\end{array}$ & $\begin{array}{l}\mathrm{R} \$ \\
0,0180\end{array}$ & $\begin{array}{c}\mathrm{R} \$ \\
0,0336\end{array}$ & $\begin{array}{l}\mathrm{R} \$ \\
0,0150\end{array}$ & $\begin{array}{l}\mathrm{R} \$ \\
0,0212\end{array}$ & $\begin{array}{l}\mathrm{R} \$ \\
0,0100\end{array}$ & $\begin{array}{l}\mathrm{R} \$ \\
0,0115\end{array}$ \\
\hline Crescimento ao ano ${ }^{12}$ & - & $4,35 \%$ & - & $2,05 \%$ & - & $8,11 \%$ & - & $\begin{array}{l}18,88 \\
\%\end{array}$ & - & $1,57 \%$ \\
\hline $\begin{array}{l}\text { Consumo de Água Bruta } \\
(\mathrm{R} \$ / \mathrm{m} 3)\end{array}$ & $\begin{array}{l}\mathrm{R} \$ \\
0,0200\end{array}$ & $\begin{array}{l}\mathrm{R} \$ \\
0,0316\end{array}$ & $\begin{array}{l}\mathrm{R} \$ \\
0,0200\end{array}$ & $\begin{array}{l}\mathrm{R} \$ \\
0,0240\end{array}$ & $\begin{array}{l}\mathrm{R} \$ \\
0,0270\end{array}$ & $\begin{array}{l}\mathrm{R} \$ \\
0,0448\end{array}$ & Sem Ol & ervação & $\begin{array}{l}\mathrm{R} \$ \\
0,0200\end{array}$ & $\begin{array}{c}\mathrm{R} \$ \\
0,0229\end{array}$ \\
\hline Crescimento ao ano & - & $2,90 \%$ & - & $2,05 \%$ & - & $6,53 \%$ & & & - & $1,52 \%$ \\
\hline $\begin{array}{l}\text { Lançamento de Efluentes } \\
\text { (R\$/Kg do DBO) }\end{array}$ & $\begin{array}{l}\mathrm{R} \$ \\
0,0700\end{array}$ & $\begin{array}{l}\mathrm{R} \$ \\
0,1106\end{array}$ & $\begin{array}{l}\mathrm{R} \$ \\
0,0700\end{array}$ & $\begin{array}{l}\mathrm{R} \$ \\
0,0719\end{array}$ & $\begin{array}{l}\mathrm{R} \$ \\
0,1000\end{array}$ & $\begin{array}{l}\mathrm{R} \$ \\
0,1790\end{array}$ & $\begin{array}{l}\mathrm{R} \$ \\
0,0700\end{array}$ & $\begin{array}{l}\mathrm{R} \$ \\
0,1164\end{array}$ & $\begin{array}{l}\mathrm{R} \$ \\
0,0700\end{array}$ & $\begin{array}{l}\mathrm{R} \$ \\
0,0803\end{array}$ \\
\hline Crescimento ao ano & - & $2,90 \%$ & - & $0,34 \%$ & - & $7,55 \%$ & - & $\begin{array}{l}28,95 \\
\%\end{array}$ & - & $1,54 \%$ \\
\hline
\end{tabular}

Quadro 1: Evolução da Cobrança de Recursos Hídricos, por fato gerador

Elaboração Própria com Base em dados da ANA

Ao considerar o valor unitário, podemos entender que o critério volume foi removido da análise e, logo, pode-se inferir que, às flutuações definidas são funções das reduções dos volumes disponíveis e da capacidade de aporte destes corpos para o recebimento dos efluentes. Logo, dentre os resultados observados, verifica-se que o Rio Parnaíba apresentou esgotamento mais elevado de todos e os de menor esgotamento foram os Rios Verde Grande e o Rio São Francisco.

\footnotetext{
${ }^{12}$ Considerando a variação como função exponencial do esgotamento do recurso e de sua contaminação com efluentes.
} 
Em termos de perfil dos principais usuários, cada bacia possui um agente demandante majoritário diferente: i) Rio Paraíba do Sul - Atividade de Siderurgia (Companhia Siderúrgica Nacional); ii) Rio São Francisco - Atividade de Transposição (Ministério da Integração Nacional - PISF); iii) Rio Doce - Atividade de Transposição (Fibria Celulose S/A); iv) Rio Paranaíba - Atividade de Saneamento (Companhia de Saneamento Ambiental do Distrito Federal - CAESB); e v) Rio Verde Grande - Atividade de Saneamento (Companhia de Saneamento de Minas Gerais - COPASA - Espinosa). Usualmente estas atividades encontram-se relacionadas ao serviço público, sendo raro a ocasião de um demandante privado ser o mais expressivo dentro do contexto analisado.

Se pela ótica das contrapartidas pelo uso do recurso, isto é, dos valores pagos em termos de vazão do recurso, os valores variam em certos parâmetros, é unicamente lógico que essa variação tem de ser, no mínimo compatível com esse esgotamento do recurso, pois, se cada vez menos recurso se encontra dispo nível a preços não mais elevados que a sua redução de disponibilidade, é criado um incentivo para seu consumo e esgotamento das quantidades parciais residuais, isto é, nada mais que a lógica da elasticidade, neste caso, uma elasticidade da demanda defrontada com o volume disponível e defrontada ao preço pela redução do recurso.

Ao analisarmos esse critério de elasticidade, por renda familiar, verifica-se que essa elasticidade se dá em forma de U, com as famílias que recebem até 2 salários-mínimos tendo elasticidade negativa de -0,62, entre 2 e 10 salários com elasticidade de $-0,16$ e, acima de 10 salários a elasticidade tornando a se ampliar para -0,22, conforme aponta Lanna (2001, p. 99). O fator de restrição orçamentária explica a redução alta na baixa renda, e o fator de consumo "extra necessidade", leia-se desperdício, é o que gera a acepção ora estruturada, de que, se o aumento do preço cobrado pelo recurso não for em proporção significativa o suficiente, o incentivo continua sendo pelo esgotamento e, a depender do caso, em ritmos ainda mais elevados.

Dentro do aspecto da cobrança, é importante destacar o setor hidroelétrico, notou-se no período de 2001 a 2018 aumento de 54,47\% na quantidades de Usinas deste setor e em termos de receita com arrecadação total, aumento de $247,16 \%$, ou, em termos de arrecadação por usina, aumento de $124,78 \%$, menor que a variação total de agentes demandantes do recurso, que, considerando a condição sine qua non de aumento de demanda pelo recurso 
energético gerado (de todas as fontes) pôde-se observar redução na base de cálculo para os volumes utilizados neste processo.

Outrossim, ainda em termos de regras para cobrança, um ponto importante a se abordar são as isenções geradas, que, apesar de serem exclusivas para o agente que controla o corpo hídrico, i.e, o seu regulador, geram externalidades dentro da situação econômica da bacia por muitas vezes negativas, por exemplo, em rios do estado do Paraná, os pequenos produtores rurais, que possuam até seis módulos fiscais, ficarão isentos da cobrança pelo direito de uso de água, sendo este benefício estendido aos demais produtores rurais, desde que o consumo seja exclusivamente destinado à produção agropecuária e silvipastoril, o que, na prática, isenta todos os usos agropecuários.

Essa isenção resulta em uma série de externalidades, conforme a seguir: i) Imediata e direta: Aumento das taxas cobradas para outros usuários; ii) Indireta e de temporalidade indefinida: Diminuição dos volumes do recurso, visto o grande atrativo para o deslocamento da atividade produtiva para a região e o incentivo a não adoção de medidas que visem a otimização do consumo do recurso, face a sua não onerosidade.

Com tudo isto elencando, a observação a ser feita é a de atraso de implantação e de processos arbitrários que vem prejudicando a efetiva manutenção do recurso, face a seus incentivos para esgotamentos, pois, se por um lado, a adoção da cobrança se dá em um pequeno grupo de bacias, a não adoção ocorre em outros e, com isso, ocorre estímulo ao esgotamento dos recursos e, mesmo que, a partir deste esgotamento o órgão responsável pela elaboração da política de arrecadação passe a efetivá-la, o retrocesso dos volumes utilizados não poderá ser cobrado e, o resultado em termos de impacto já se consolidou.

Ante o exposto, pode-se analisar a real efetividade desta cobrança frente a redução do recurso hídrico disponível dentro do contexto daquela bacia, considerando que, em termos ideias deveria haver a ideia de circuito fechado, isto é, até o recurso consumido deveria retornar tratado ao corpo do qual foi removido, se a redução deste recurso foi de tamanho tal elevado que sua disponibilidade é crítica, os valores cobrados e todas as demais políticas aplicadas naquela localidade foram inefetivas ou, na melhor das hipóteses, não tão efetivas quanto poderiam ser se fossem adotadas metodologias de cobrança que considerassem esse impacto.

A disponibilidade dos recursos nas principais fontes de arrecadação, isto é, Ceará, Rio de Janeiro, Alagoas se encontram em estado de pobreza de disponibilidade (menos de 
$2.500 \mathrm{~m} 3$ por habitante no ano) e São Paulo encontra-se em estágio de equilíbrio (entre 2.500 e $5.000 \mathrm{~m} 3$ por habitante no ano), entretanto beirando o estágio de pobreza (disponibilidade de $2.913 \mathrm{~m} 3$ por habitante no ano), segundo dados de Gomes (2004, p. 6).

Toda a tratativa da escassez incita a existência ou, possibilidade de surgimento, de conflitos para a forma como se distribui o recurso e seu consumo efetivo, este efeito é inerente a todo o sistema econômico capitalista, especialmente quando referenciado a um recurso de manutenção da vida, em diversos de seus aspectos, a redução da disponibilidade do recurso resulta, com reflexo no aumento do preço, que esse esgotamento se dará, evidentemente e conforme elencado anteriormente, mas não por todos aqueles que demandam o recurso, apenas por aqueles com capacidade financeira de explorar essa oportunidade de esgotamento. Ao longo da história diversos são os registros destes conflitos, alguns inclusive sendo travados no campo do belicismo, e. $\mathrm{g}$ as pelejas entre Estados Unidos e México, entretanto, analisando o contexto em destaque, isto é, o brasileiro, São Paulo é um exemplar destas disputas, com a capital sendo abastecida pelos mananciais que formam a bacia hidrográfica do rio Piracicaba, gerando disputas no campo político e jurídico entre os municípios e a companhia de saneamento, visto que, os agentes de menor poderio econômico da relação foram prejudicados em detrimento deste abastecimento, tendo seu fornecimento reduzido e, em alguns casos, cessado, para que a capital fosse favorecida.

Logo, toda a derivação desenvolvida neste capítulo se encerra com a validação das premissas estabelecidas, os locais que geraram a menor variação de custo para o consumo do recurso foram aqueles que tiveram a exaustão do recurso de maneira mais significativa, resultando em redução da qualidade e quantidade do recurso disponível a níveis que, muitas das vezes, não são de possível retorno, isto é, o incentivo ao esgotamento se mascara dentro da ajustes insignificantes pelo consumo do recurso, ficando a ideia de que os valores cobrados são condizentes com a política e são medidas de proteção e manutenção do recurso, quando na verdade, correspondem a incentivos econômicos para a redução da disponibilidade intertemporal do recurso, gerando escassez e não remunerando efetivamente para que o mesmo possa ser recuperado em momento futuro.

\section{Uso sustentável da água e cobrança}


Políticas públicas de controle da utilização de recursos naturais visam atender o aspecto da sustentabilidade na promoção do desenvolvimento da sociedade. Os objetivos da Cobrança pelo uso da água (indicação do valor da água, incentivo do seu uso racional e obtenção de recursos financeiros para a recuperação de bacias, segundo ANA (2019, p. 7)) estão associados à promoção de um uso sustentável de tais recursos.

De acordo com Garcia (2019, p. 189-209), a água “é um recurso renovável, mas relativamente escasso em algumas regiões do planeta. No Brasil, mesmo tendo-a em abundância, há um mau uso caracterizado tanto pelo uso inadequado, ou inescrupuloso, o que leva à degradação desse recurso.”

É indissociável a importância da sustentabilidade e do pensamento sustentável na manutenção das atividades humanas, e Juarez de Freitas (2012) a defende como um princípio constitucional:

\footnotetext{
"Reitere-se, bem a propósito, o conceito de sustentabilidade aqui adotado: é o princípio constitucional que determina, independentemente de regulamentação legal, com eficácia direta e imediata, a responsabilidade do Estado e da sociedade pela concretização solidária do desenvolvimento material e imaterial, socialmente inclusivo, durável e equânime, ambientalmente limpo, inovador, ético e eficiente, no intuito de assegurar, preferencialmente de modo preventivo e precavido, no presente e no futuro, o direito ao bem-estar." (FREITAS, 2019)
}

$\mathrm{O}$ autor define as dimensões da sustentabilidade, mostrando sua importância em cada sentido. Dentre tais dimensões, destaca-se aqui a dimensão econômica, que traz à luz da demonstra que há uma ponderação, ou trade-off, entre eficiência e equidade, isto é, o sopesamento fundamentado dos benefícios e dos custos diretos e indiretos (externalidades)". Salienta que a economicidade de um formato de empreendimento deve ser medida em conjunto com seus resultados (consequências) de longo prazo.

Assim, ao fazer um comparativo com o uso da água, que hoje sofre alterações de curto e longo prazo com o seu formato de utilização, deve-se pensar em uma forma sustentável de mudar tais consequências, e medi-las desde já ao se pensar no real valor da água. Ao fazer os devidos cálculos de preço que deve ser pago pela água, deve-se levar em conta algo além do que possa ser considerado um valor simbólico para esse bem, sob risco de ferir o princípio constitucional da sustentabilidade.

Em relação ao valor da água, Garcia (2018, p. 203) buscou analisar se a água deve ser considerada um bem ou uma mercadoria. Chegou ao entendimento de que deve ser vista 
como um bem fundamental "porque sua acessibilidade deve ser garantida a todos e a cada um por ser objeto de tantos outros direitos fundamentais e bens fundamentais e que por isso, não são submetidos à lógica de mercado tal como acontece com as mercadorias".

O princípio da sustentabilidade também se encontra nas dimensões social, ética, ambiental e jurídico-política. A primeira diz respeito ao fato de que não se pode admitir um modelo de desenvolvimento excludente e iníquo, em que se cogita a sobrevivência de poucos, já que a insustentabilidade é, por natureza, excludente, segundo Freitas (2012, p. 5861). A segunda está na ideia de que uma atitude eticamente sustentável é aquela que pode produzir bem-estar duradouro (tanto intimamente quanto na interação com a natureza).

A dimensão ambiental será pelo direito intergeracional ao meio ambiente limpo, para Freitas (2012, p 64-71) levando-se em conta que não pode haver qualidade de vida em um ambiente degradado, ou em seu limite. Por fim, na dimensão jurídico-política, a sustentabilidade "altera a visão global do Direito, ao incorporar a condição normativa de um tipo de desenvolvimento, para o qual todos os esforços devem convergência obrigatória e vinculante" - assim, seria considerada desproporcional e antijurídica qualquer omissão que cause injustos danos intrageracionais e intergeracionais.

Outro conceito importante que se pode discutir é o de mínimo existencial ecológico trazido por Fensterseifer (2008, p. 264). Tal conceito está em consonância com a ideia de que há um mínimo existencial humano, que possui como integrantes a moradia digna e saúde básica, por exemplo, dentro do qual deve ser considerada também a qualidade ambiental. Basicamente, trata-se "de construir a ideia de um bem-estar existencial que tome em conta também a qualidade ambiental".

A água, como bem essencial à manutenção da vida, se enquadrará em vários aspectos do mínimo existencial (saúde básica, saneamento básico, alimentação adequada), tornando inegável a importância de sua preservação. O autor salienta que "para aquém desse limite existencial, a vida (...) pode ainda resistir, mas a existência humana não atingirá os padrões exigidos pela sociedade" conforme aponta Fensterseifer (2008, p. 269).

Dessa forma, há vários pontos a se pensar sobre como a omissão dos estados e da própria União sobre os usos exagerados da água prejudicará as próximas gerações e já prejudica gerações atuais que lidam com conflitos pelo uso da água. Vários exemplos podem ser trazidos em relação a tais conflitos, com o da Bacia dos rios Verde e Jacaré (sub-bacia do Rio São Francisco), que possui baixa disponibilidade de água em consequência da pouca 
abundância de chuvas (clima semiárido do sertão nordestino) e da elevada densidade de poços para captação de água para irrigação. Como exemplos de seus conflitos, cita-se:

\begin{abstract}
$\checkmark \quad$ A superexploração da água para irrigação no Platô do Irecê; é usual no Platô do Irecê o estabelecimento de diversos poços muito próximos uns dos outros, ocorrendo comprometimento da disponibilidade;

$\checkmark \quad$ Entre irrigantes do Dipim/Codevasf e Embasa, pelo uso das águas da barragem de Mirorós;

$\checkmark \quad$ A expansão de cultivo ao longo do riacho Bandeira, a montante da sede de Barra do Mendes;

$\checkmark \quad$ Excessivo número de pequenos barramentos ao longo do rio Verde, gerando conflitos com as comunidades ribeirinhas. (INEMA, 2017, p. 75)
\end{abstract}

Logo, o que ocorre nessa região, em especial no Platô do Irecê ${ }^{13}$, é a prática da agricultura como principal atividade econômica, e a escassez da água está levando a uma migração para outras áreas em busca de aumento da região irrigável. É inegável o efeito rápido e possivelmente devastador do uso da água.

Pode-se contra-argumentar que tal atividade econômica é essencial para os habitantes daquela região (desprovida de atividades com maior valor agregado e urbanização, por exemplo), como justificativa para tal uso desenfreado da água. Garcia ${ }^{14}$ traz que o lado social deve ser observado, além dos enfoques ambiental e econômico da sustentabilidade.

No entanto, deve-se possuir uma visão detalhada de tal ponto, para não cair no que Freitas (2013, p. 138) chama de falácias da sustentabilidade, que são "erros lógicos, conscientes ou inconscientes, enganadores e/ou autoenganadores, que servem para ludibriar e formar pré-compreensões equivocadas, conducentes a preconceitos ilegítimos, estereótipos e más decisões".

Dentre tais falácias, a que mais se caracterizaria em tal exemplo seria a argumentativa do medo ou da ameaça:

\footnotetext{
13 "No Platô de Irecê concentram-se as atividades agrícolas, inclusive a agricultura irrigada de cebola, mamona, tomate, pimentão. A água para esta atividade é obtida quase exclusivamente a partir de poços. As terras são em geral, de pequena extensão e de aproveitamento intensivo. Os proprietários, sua família e poucos empregados fazem o manejo. Usualmente a propriedade envolve área de criação de poucas cabeças de gado bovino/ovino, cultivo de sequeiro (usualmente milho) e cultivo irrigado." BAHIA. Instituto do Meio Ambiente e Recursos Hídricos - INEMA. Plano de Recursos Hídricos das Bacias Hidrográficas dos rios Verde e Jacaré PRHVJ. p. 73.

14 "Percebe-se, portanto, que nos países desenvolvidos o enfoque dado à sustentabilidade é mais direcionado ao ambiental e o econômico, fugindo da real necessidade dos países em desenvolvimento, que necessitam observar além desses dois enfoques ainda o lado social, pois se a população não possui condições mínimas de vida, não haverá preocupação em preservação ambiental, pois a preservação da vida imediata se fará mais urgente." GARCIA, Denise Schmitt Siqueira. O caminho para sustentabilidade. In, GARCIA, Denise Schimitt Siqueira (org.). Ebook UNIVALI, 2015.. p. 25.
} 
"Nociva, igualmente, é a falácia argumentativa do medo ou da ameaça, diversamente do sadio dispositivo de alerta. Traduz-se pelo apelo irracional e alarmista às ameaças catastróficas ou ao pânico para distorcer a eleição das premissas, ou seja, para, mediante constrangimento ou intimidação, obter conclusão indevida. (...) Por exemplo, diz-se que faltarão recursos para alimentar a população se determinada decisão protetiva do ambiente for tomada. [...]"(FREITAS, 2012, p. 144-145)

Também pode-se considerar a "falácia ad populum" e a falácia da misericórdia. A primeira consistiria na apelação a sentimentos populares para substituir ou suprir a falta de consistência argumentativa - o autor considera que "a irrenunciável defesa do bem de todos nem sempre coincide com a preponderância dos sentimentos transitórios e confusos das populações assimetricamente informadas”, aponta Freitas (2012, p.140-141). A segunda está ligada à anterior, consistindo no apelo a sentimentos de compaixão para lastro de conclusões erradas e insustentáveis, como no sentido de fazer vista grossa a pesadas infrações ambientais.

Assim, tal argumento não pode ser utilizado como justificativa para ignorar o princípio constitucional que é a sustentabilidade, acreditando que um tipo de benefício é melhor que o outro. Não apenas porque, como visto anteriormente, a sustentabilidade é também um apelo social ligado a direitos fundamentais, mas também porque a escassez de água no futuro irá comprometer inclusive a atividade econômica da região. Logo, o ideal é buscar uma alternativa mais sustentável que vá proporcionar mais segurança para a população no futuro, como o incentivo a atividades que possam ser realizadas no futuro e com maior valor agregado.

Quando se pensa em casos em que há a aplicação do instrumento de cobrança pelo uso dos recursos hídricos, mas isso é acompanhado de uma esquiva da correta e séria implementação, como a aplicação de isenção a uma boa parte do uso da água (caso do estado do Paraná, que isenta todo o uso aplicável agrícola, como mostrado neste trabalho), pode-se pensar em uma espécie de retrocesso ambiental, conceito trazido na obra de Fensterseifer:

“[...] A proibição de retrocesso ambiental, da mesma forma como ocorre com a proibição de retrocesso social, está relacionada ao princípio da segurança jurídica, da proteção das confiança ou mesmo de previsibilidade no enquadramento normativo das relações jurídicas (as garantias constitucionais do direito adquirido, do ato jurídico perfeito e da coisa julgada, bem como os limites materiais à reforma constitucional são expressão do princípio constitucional da segurança jurídica), o que se apresenta como um traço característico da conformação do Estado de Direito. [...]" (FENSTERSEIFER, 2008, p. 258) 
É certo que a pressão dos principais grupos usuários de água - grandes usuários sobre os políticos responsáveis pela implementação da cobrança é um grande fator contribuinte para tal "retrocesso", bem como para a não aplicação do instrumento em muitos corpos hídricos que vêm sendo deliberadamente utilizados. Para o autor citado anteriormente, o que determinaria a proibição do retrocesso é a subordinação do legislador infraconstitucional ao comando normativo constitucional, por conta da supremacia da Constituição. No entanto, a operacionalização dessa argumentação, a ver pela aplicação do instrumento de cobrança, está sendo limitada.

\section{Considerações finais}

A gestão dos recursos hídricos no Brasil demorou a se implementar de forma mais séria, sendo que no período colonial tinham aspecto unicamente econômico no sentido de viabilizar a exploração do país enquanto colônia. Com a instituição da Política Nacional de Recursos Hídricos, a gestão passou a ser pensada de forma integrada com foco em reduzir os conflitos de uso e garantir a qualidade e quantidade da água para suprir as demandas (atuais e futuras) pelo recurso.

Entre as soluções apontadas pela PNRH, estão alguns instrumentos de gestão, como a Cobrança pelo uso dos recursos hídricos, que tem como premissas a indicação do valor da água, o incentivo do seu uso racional e a obtenção de recursos financeiros para a recuperação de bacias hidrográficas.

Para a implementação, são utilizados aspectos que, a priori são de caráter técnico, com definição de comitês de pesquisa, mas que, pela característica inerente ao próprio sistema de gestão, ao conferir ampla representatividade, acaba por ceder a pressões políticas e, tomar atitudes que vão de encontro a segurança do recurso, permitindo seu esgotamento e a redução de sua qualidade, como às isenções da atividade de agricultura.

O sistema conforme consolidado hoje apresenta gargalos para a efetiva implementação da gestão dos recursos hídricos de forma a incentivar o consumo racional, o primeiro decorre do atraso da implantação, com corpos d'água ainda sem sistema de cobrança implantados e outros recém implantados, a inferência é de que a prática é recente e ainda existe bastante espaço para melhoria. 
O segundo ponto decorre dos valores inexatos cobrados à título de taxas, que não condizem com a redução real do recurso disponível, incentivando de maneira escusa (por aparentar estar cobrando um valor de ajuste justo) este possível esgotamento do recurso.

Nesse sentido, considerando os aspectos relacionados à sustentabilidade e às condições para seu alcance através da utilização dos recursos naturais, pode-se dizer que ainda há um grande caminho a ser percorrido a nível de gestão das bacias e, por conseguinte, da implementação e efetiva cobrança. Não se trata de enxergar a água como uma mercadoria, mas de entender seu valor enquanto bem público que está sujeito à escassez e que pode alterar de forma significativa o bem-estar e o desenvolvimento da sociedade.

\section{Referências}

AGÊNCIA Nacional de Águas e Saneamento Básico - Ministério do Meio Ambiente. Cobrança pelo uso dos recursos hídricos. Cadernos de Capacitação: volume 7. Brasília-DF: ANA, 2014.

AGÊNCIA Nacional de Águas e Saneamento Básico (ANA). Cobrança pelo uso de recursos hídricos. Brasília: ANA, 2019.

AGENCIA Nacional de Águas e Saneamento Básico (ANA). O que é o SINGREH? Disponível em: <https://www.ana.gov.br/aguas-no-brasil/sistema-de-gerenciamento-derecursos-hidricos /o-que-e-o-singreh> Acesso em 27/05/2021.

BARBIERE, José Carlos; GOMES, Jesus de Lisbo a. Gerenciamento de recursos hídricos no Brasil e no estado de São Paulo: um novo modelo de política pública. EBAPE-FGV. 2004

BRASIL. Presidência da República. Lei No 9.433, de 8 de janeiro de 1997. Institui a Política Nacional de Recursos Hídricos. Capítulo IV, Seção I, Arts. $6^{\circ}$ e $7^{\circ}$. Disponível em: http://www.planalto.gov.br/ccivil_03/leis/19433.htm. Acessado em: 18.05.2021.

FENSTERSEIFER, Tiago. Direitos fundamentais e proteção do ambiente. A dimensão ecológica da dignidade humana no marco jurídico constitucional do Estado Democrático de Direito. Porto Alegre: livraria do advogado Editora, 2008.

FOCAULT, Michael. Vigiar e Punir. Petrópolis, RJ: Vozes. Original publicado em 1975 
MENGER, Carl. Princípios da Economia Política. LeBooks. 2017

FREITAS, Juarez. Sustentabilidade - Direito ao futuro. Belo Horizonte: editora, 2012.

GARCIA, Denise Schimitt Siqueira. Água: bem ou mercadoria? In: SOUZA, Maria Cláudia

S. A. POMPEU, Gina V. M. FREITAS, Ana C. P. Gestão das águas. Rio de Janeiro: Lumen Juris, 2018. p. 189-209.

GARCIA, Denise Schimitt Siqueira. O caminho para sustentabilidade. In: GARCIA, Denise Schimitt Siqueira. Ebook UNIVALI, 2015.

LANNA, Antonio Eduardo. Economia dos Recursos Hídricos. Instituto de Pesquisas Hídricas - UFRGS. 2001

PASOLD, César Luiz. Metodologia da Pesquisa Jurídica: teoria e prática. 14 ed. Florianópolis: EMais, 2018.

ROSA, A. M. R.; GUARDA, V. L. M. Gestão de recursos hídricos no Brasil: um histórico. Revista Direito Ambiental e sociedade, v. 9, n.2, maio/ago. 2019. p. 197-220. Disponível em: http://www.ucs.br/etc/revistas/index.php/direitoambiental/article/view/7886/3967. Acessado em: 05.05.2021. 